\title{
FUTURE IMPACT OF CLIMATE CHANGE ON BUILDINGS' ENERGY CONSUMPTION IN SUBTROPICAL CLIMATES
}

\author{
MARTA VIDERAS, SERGIO G. MELGAR, ANTONIO S. CORDERO \\ \& JOSÉ MANUEL ANDÚJAR MÁRQUEZ \\ Industrial and Environmental Science and Technology Program, University of Huelva, Spain
}

\begin{abstract}
The growing concern about global climate change extends to different professional sectors. In the building industry, the energy consumption of buildings has become a vulnerable factor due to the direct relationship between the outside temperature and the energy needed to cool and heat the internal space. This paper aims to estimate the influence of time evolution and different climate-change scenarios on the energy behaviour of a Minimum Energy Building (MEB) dwelling in a subtropical climate located in Malaga, southern Spain. The future building energy consumption has been predicted using dynamic building energy simulation software tools. To quantify the impact, an online, open access software has been used to calculate the future weather data through a general circulation model (GCM) and a mathematical method of transformation. Projected climate data were obtained in three time periods 2020s, 2050s and 2080s), based on four emission scenarios defined by the Intergovernmental Panel on Climate Change (IPCC): B1, B2, A2, A1F1. The different energy simulations carried on show clearly future trends of growth in total building energy consumption and how actual building designers could be underestimating the problem of cooling in the subtropical zone. Electricity demand for heating is expected to decrease almost completely, while electricity demand for cooling increases considerably. The changes predicted are significant in all scenarios and periods, concluding an increase of between $48-83 \%$ in total energy consumption during the building life cycle.
\end{abstract}

Keywords: global climate change, building energy simulation, building energy consumption, future weather data files, green-house gas emission, energy impacts, EnergyPlus, uhuMEB

\section{INTRODUCTION}

Climate change is one of the greatest challenges facing humanity. Greenhouse gas (GHG) emissions are growing at an alarming rate and this rising trend is associated with human activities. The building industry contributes up to one third of total greenhouse gas emissions, mainly due to the burning of fossil fuels in its operation, being responsible for at least $40 \%$ of the total energy consumption in the European Union (EU) [1]. While the rate of construction is constantly growing, buildings are increasing their energy demands to satisfy the needs of its inhabitants. The Intergovernmental Panel on Climate Change (IPCC) estimates a temperature increase of $1-7^{\circ} \mathrm{C}$ during the period $1960-2100$ using various GHG emission scenarios [2]. Globally, cooling energy consumption is expected to increase and heating energy consumption to decrease, but both would change for each climate zone. Depending on geographical regions and building types, the impact of climate change will be different. Therefore, impact investigations of climate change in this sector are needed to provide some parameters to outline a strategic approach to make buildings more energy efficient in a future uncertain climate.

Research about the impact of climate change on the energy consumption of buildings has been carried out for many years. Researchers often input a file of projected future weather data from a certain greenhouse gas emission scenario and a building model into simulation software to estimate future energy use in the building. In order to simulate the general effects of climate change, some general circulation models (GCM) were developed by the scientist community. These mathematical models are based on the Navier-Stokes equations which 
describe the atmosphere-ocean circulation. These models provide future climate data such as monthly change in dry bulb temperature, variation in daytime temperature, relative humidity, wind speed and solar radiation [3].

The first investigations which simulated the impact of climate change on buildings directly acquired the climate information from these models. But their limitations, especially because they are global models, require the use of algorithms to downscale the values obtained. The scientific community developed a large number of mathematical methods that were used for this purpose. Some downscaling methodologies like regression methods, weather pattern-based approaches, stochastic weather generators (statistical downscaling methods) and limited-area modelling were the first methods proposed [4]. However, the complexity of statistical models, which require linear equations of third to fifth order and their computational cost, led to develop dynamic models such as the morphing method, which is the best known and most widely used method in this field [5]. Following this procedure, different investigations were carried out to study the impact of climate change on buildings located in different regions: Wang et al. [6] in Sydney, Chan [7] in Hong Kong, Zhu et al. [8] in Shanghai, and Wang and Chen [9], Shen [10] and Wang et al. [11] in several cities in the USA.

The latest research uses new tools that are freely accessible on the Internet and provide future climate data with an already intrinsic mathematical methodology, saving researcher's time in the process of generating data. The first climate change weather generator tool was developed by Jentsch et al. [12], [13]: CCWorld-WeatherGen. Based on Microsoft Excel ${ }^{\mathrm{TM}}$, this tool integrates a global circulation model and a mathematical method. The software allows the generation of future meteorological data in the formats used by the simulation software: Typical Meteorological Year (TMY2) and EnergyPlus ${ }^{\mathrm{TM}}$ Weather (EPW). Sabunas and Kanapickas [14] used this software to calculate the energy consumption of several residential buildings in Lithuania. Jiang et al. [15] applied it to evaluate electricity and gas consumption in commercial buildings in different climate zones in the state of Florida. Subsequently, the University of North Florida developed a new tool: Weather Morph: Climate Change Weather File Generator, which was developed employing the ideas and methodology behind the CCWorldWeatherGen tool. Some modifications have been made to this website that differ from the original to enhance overall performance like the addition of three more experiment scenarios and an overall reduction in time to run calculations. Jiang et al. [16] used this software to evaluate the impact of global warming in different cities around the world covering various types of climate.

The variation of weather conditions due to global warming may have significant impact on the energy consumption of buildings. This needs to be investigated according to different periods of time, different warming scenarios and different climate conditions. In this research, the authors applied the current methodology used by the scientific community to estimate the impact of climate change on passive and energy-efficient housing in a very characteristic climate typical of southern Spain, the subtropical climate. Other researchers have carried out studies on the impact of climate change on this type of climate, but in other locations, such as Hong Kong [17], [18] and Brazil [19]. However, the results cannot be extrapolated to cities on different continents as a peculiarity of this type of climate is that depending on the latitude, altitude, or even proximity to the coast, the climate patterns vary.

\section{METHODOLOGY}

This research uses a four-step methodology to quantify the impact of climate change on building energy consumption (Fig. 1). 


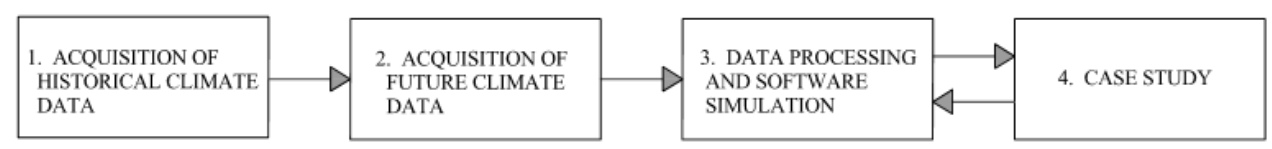

Figure 1: The 4-step methodology flux diagram.

\subsection{Acquisition of historical climate data}

A historical climate reference was settled as first step to generate future weather archives. These historical climate data were derived from weather measurements made between 1961 and 1990 by more than 7700 weather stations around the world. They can be obtained from different sources depending on the country of origin or the simulation package used. In an international context, SWERA, Solar and Wind Energy Resource Assessment, funded by the United Nations Environment Programme, provides typical weather year data for 156 locations in 14 countries and IWEC, International Weather for Energy Calculations, from Numerical Logics and Bodycote Materials Testing Canada, provides typical weather files for 227 locations worldwide.

SWEC's data files, Spanish Weather for Energy Calculations, were used for this research. These are 52 weather files, one for each provincial capital, which were generated using historical meteorological data from the Spanish National Institute of Meteorology. These historical climate files are available on the EnergyPlus ${ }^{\mathrm{TM}}$ website [20] created by the United States Department of Energy (DOE).

\subsection{Acquisition of future climate data}

The process of generating future climate files has been done using the Weather Morph: Climate Change Weather File Generator tool available on the internet and free of charge [21]. This website processes present-day EPW files and performs several calculations to produce climate change weather files intended to be used in building energy consumption simulation programs. Calculations performed are based on the morphing methodology for the transformation of weather data. Furthermore, the global circulation model HadCM3 files, based on the model of the Hadley Centre of the United Kingdom Meteorological Office, are pre-loaded in this software. This tool allows the simulation of the climate of a locality in three time frames: 2020, 2050 and 2080 and under the four GHG emission scenarios experienced and reported by the IPCC. These emission scenarios: B1, B2, A2 and A1F1 have been widely used by the scientific community in the previously exposed literature to analyse the future energy demands of buildings. These scenarios are based on social trends, economic growth, technological development and demographic factors. Thus, 12 future climate archives have been obtained in different decades and different scenarios depending on the social, economic, technological and demographic progress of the planet. Scenario B1 is the most favourable, whose simulation is based on a more homogeneous society involved in global sustainability. It emphasizes global solutions to economic, social and environmental problems. Scenario B2 focuses on a more fragmented society that prefers to solve local rather than global problems. Scenario A2 simulates a society based on self-sufficiency, where economic growth is regional and technological development is slower than in other families of scenarios. Finally, A1F1 is the most pessimistic scenario, which is characterized by rapid global economic growth and continued use of fossil fuels [22]. 


\subsection{Data processing and software simulation}

The future climate files obtained from the Weather Morph: Climate Change Weather File Generator tool were given in TMY2 and EPW format, in order to be automatically integrated by the different building energy simulation software: EnergyPlus ${ }^{\mathrm{TM}}$, Visual $\mathrm{DOE}^{\mathrm{TM}}$ or TRNSYS ${ }^{\mathrm{TM}}$. The software used for building energy simulation was DesignBuilder ${ }^{\mathrm{TM}}$ which uses EnergyPlus ${ }^{\mathrm{TM}}$ as a data calculation engine. DesignBuilder ${ }^{\mathrm{TM}}$ was chosen because it can simulate the current environmental and energy performance of buildings, including energy consumption, $\mathrm{CO}_{2}$ emissions and indoor hygrothermal conditions. In addition, this tool allows to estimate the size of heating and cooling systems by the ASHRAE heat balance method and provides specific comfort models. EnergyPlus ${ }^{\mathrm{TM}}$ has been tested and validated to ANSI/ASHRAE standards and is commonly used by the scientific community. In order to study the variations of the climatic conditions in the different scenarios and periods of time Elements tool, from the Rocky Mountain Institute, was used, which allows to visualize, create and edit EPW files.

\subsection{Case study}

The authors of this research work have experience in the field of minimum energy buildings (MEB) in subtropical climates, both in research projects [23]-[25] and in projects for public administrations, private companies and individual customers. The case study chosen for this research is a dwelling that was previously optimized in energy terms, for increasing its level of efficiency to the uhuMEB standard. In this preliminary phase, two of the requirements of the uhuMEB methodology were fulfilled:

1. The energy demand for heating, ventilation and air conditioning (HVAC) of the building must be less than $10 \mathrm{kWh} / \mathrm{m}^{2} \mathrm{y}$.

2. The total primary energy demand of the building must be less than $80 \mathrm{kWh} / \mathrm{m}^{2} \mathrm{y}$.

This single-family house (Fig. 2), is located in the climate zone of Csa, according to the Köppen-Geiger climate classification. This subtropical climate is characterised by hot, dry summers, mild, wet winters and variable spring and autumn temperatures and rainfall. This building is located in a residential neighborhood in the metropolitan area of the city of Malaga, in southern Spain.
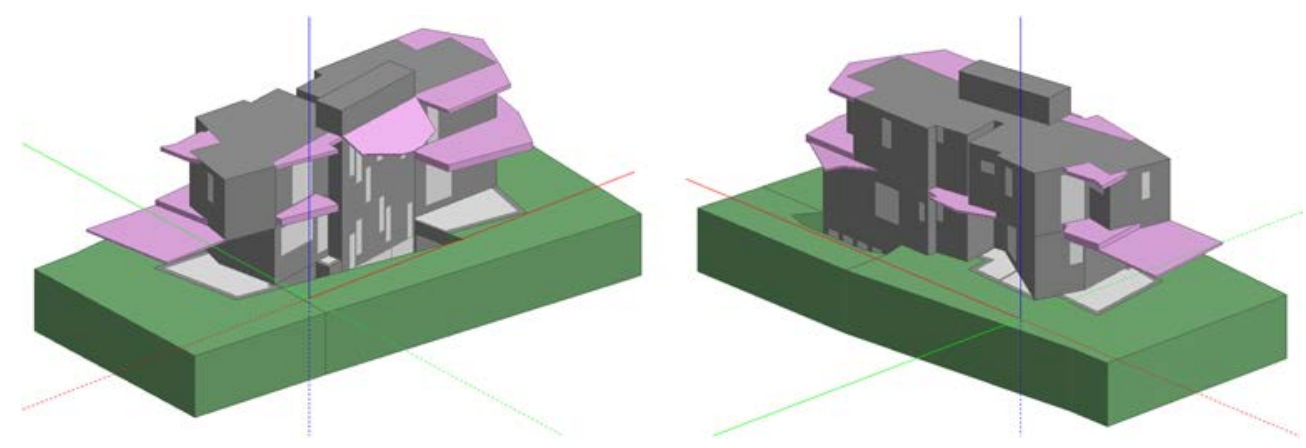

Figure 2: Designed dwelling as modelled by DesignBuilder ${ }^{\mathrm{TM}}$. 
The historical weather files of Malaga, measured between 1961 and 1990 were used to make the current simulations by DesignBuilder. Those show an average temperature of $18^{\circ} \mathrm{C}$ (Fig. 3). The monthly average varies between $12.2^{\circ} \mathrm{C}$ in January and $25.3^{\circ} \mathrm{C}$ in August. Along the year, the house is exposed to a very wide temperature range. The average annual humidity is $66.1 \%$, reaching its maximum $(71.9 \%$ ) in December. On the other hand, the average annual rainfall is $524 \mathrm{~mm}$ (the monthly average varies from $0 \mathrm{~mm}$ in July to $101 \mathrm{~mm}$ in November).

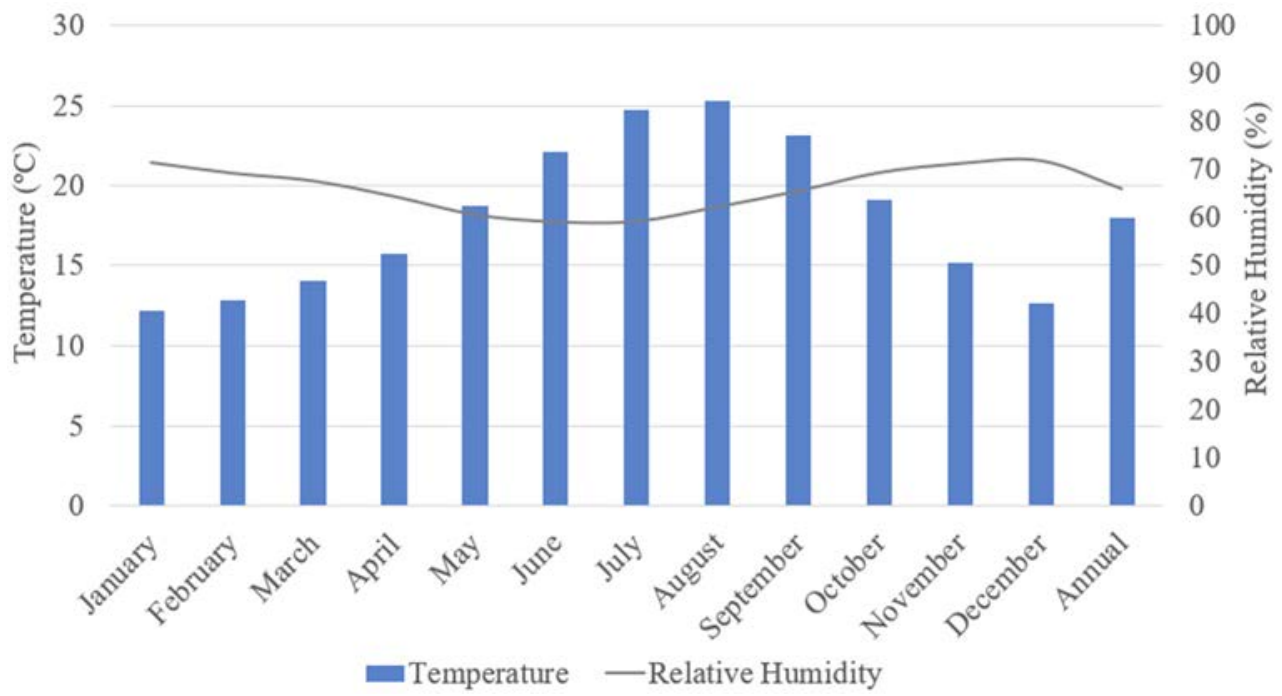

Figure 3: Baseline temperature and relative humidity in Malaga.

Outdoor climatic conditions are decisive for energy efficiency in buildings. The complexity of optimising the consumption of a building in a subtropical climate lies in the variability of these conditions. In a cold climate the main objective is to accumulate heat inside the building through solar radiation and indoor thermal loads. Nevertheless in subtropical climates, depending on the season, the building needs to conserve heat, evacuate it or even exchange it with the outside. Therefore, it is necessary to modulate the strategy of air conditioning along the year, which complicate the process of buildings thermoregulation in this type of climate.

According to the uhuMEB methodology, the influence of the building envelope and the operation of the building's HVAC systems were analysed using the DesignBuilder ${ }^{\mathrm{TM}}$ tool. The thermal transmittance of the opaque envelope was studied to achieve a $U e<0.3 \mathrm{~W} / \mathrm{m}^{2} \mathrm{~K}$. For this purpose, $14 \mathrm{~cm}$ of expanded polystyrene (EPS) was prescribed inside the thermal envelope chamber. The thermal transmittance of the semi-transparent envelope was set at $1.1 \mathrm{~W} / \mathrm{m}^{2} \mathrm{~K}$ by using a low emission glass with argon chamber and PVC frames. On the other hand, the HVAC systems were pre-dimensioned by choosing a Split system (for heating and cooling), a mechanical ventilation system with a high-efficiency heat recovery and a motorized natural ventilation system.

Cause of the characteristics of the subtropical climate, the building must operate in three different climatic conditions: December, January and February as cold climate; June, July, August and September as warm climate; and the rest of year as temperate climate. 
This work propose an algorithm for the operation of the HVAC systems, so that be regulated according to the external and internal temperature measured by sensors. In this way, the external climatic conditions determine whether the building operate hermetically or partially open by exchanging heat with the outside. Using the statistical model of adaptive comfort by Nicol and Humphreys [26], the range of indoor temperatures $\left(20-24^{\circ} \mathrm{C}\right)$ that are comfortable for users in this particular location was calculated. Fig. 4 shows the general algorithm used to carry out the proposed methodology:

1. If the outside temperature is within the comfort range previously established, the natural ventilation system is activated. This allow the house to exchange excess heat or cold, thermoregulating its inside without energy consumption. During summer period, the comfort range is made more flexible $\left(18-24^{\circ} \mathrm{C}\right)$, favouring the activation of natural ventilation during summer nights.

2. If the outside temperature is out the stablished comfort range; the mechanical ventilation system is activated. This prevents the waste of energy due to the simultaneous operation of both vents. During periods of indoor thermal discomfort, the cooling and heating systems are activated and work in conjunction with the mechanical ventilation.

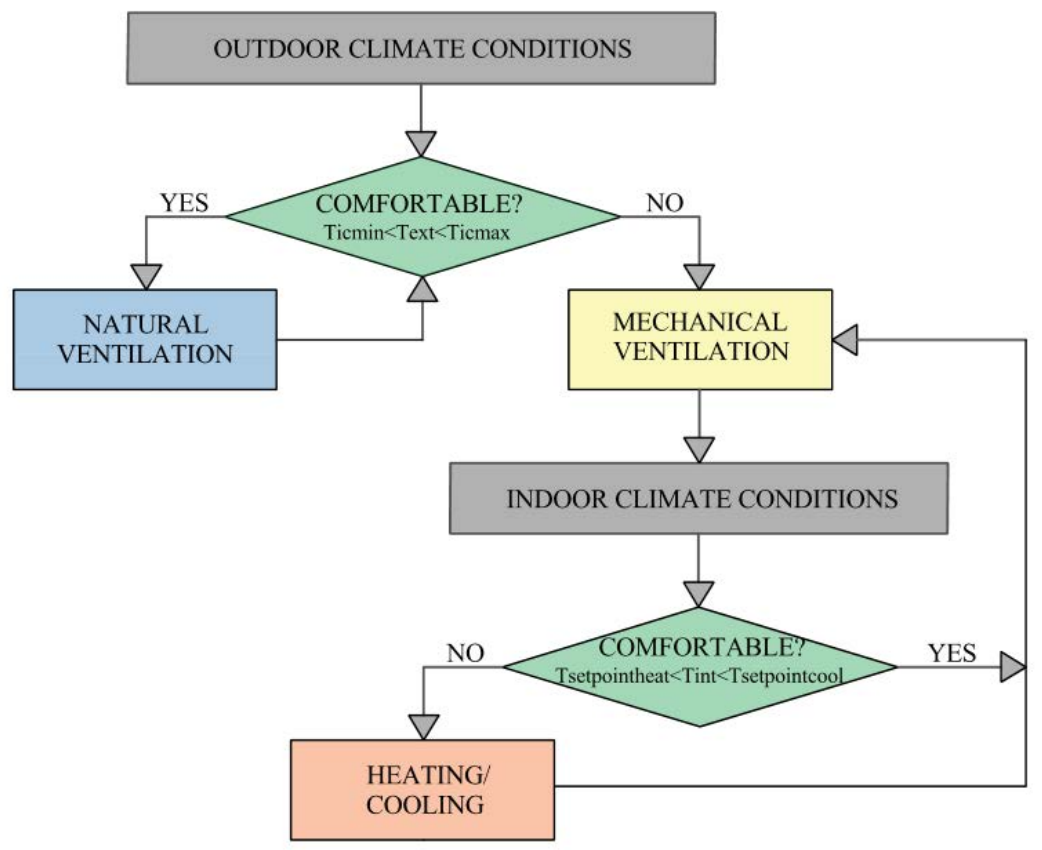

Figure 4: Algorithm for the operation of the HVAC systems.

Fig. 5 and Table 1 show how the two requirements stipulated in the uhuMEB methodology were achieved. The energy demand for heating barely reached $1.5 \mathrm{kWh} / \mathrm{m}^{2}$ while the demand for cooling exceeded $7 \mathrm{kWh} / \mathrm{m}^{2}$, but neither of these demands were higher than $10 \mathrm{kWh} / \mathrm{m}^{2}$ per year. The total primary energy consumption was $74.4 \mathrm{kWh} / \mathrm{m}^{2}$, which is less than the 80 $\mathrm{kWh} / \mathrm{m}^{2}$ per year stipulated by the uhuMEB standard. 


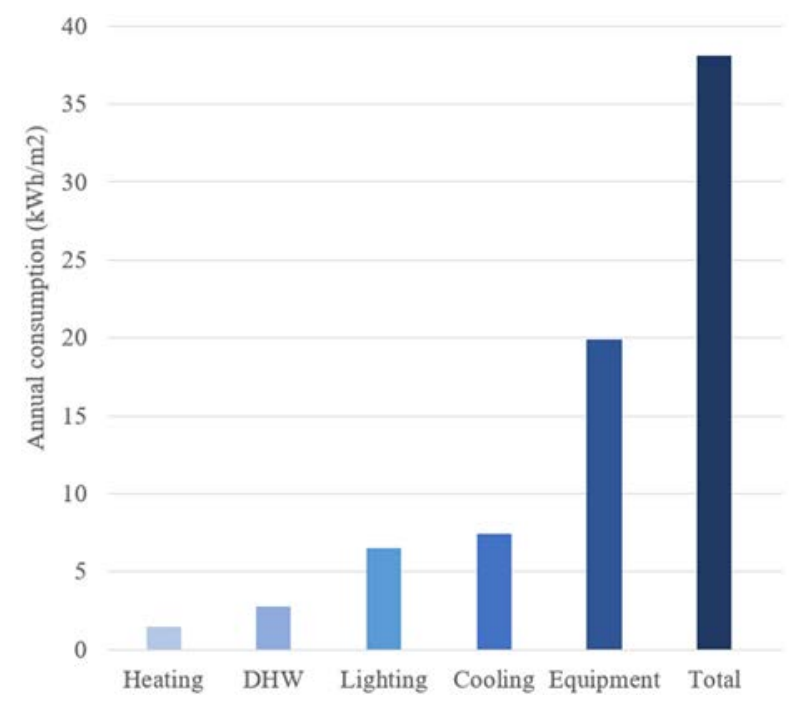

Figure 5: Current annual electricity consumption per year.

Table 1: Summary of current annual electricity consumption per year.

\begin{tabular}{l|ccc}
\hline \multicolumn{2}{c}{$\begin{array}{c}\text { Annual consumption } \\
\mathrm{kWh} / \mathrm{m} 2\end{array}$} & $\begin{array}{c}\text { Conversion } \\
\text { factor }\end{array}$ & $\begin{array}{c}\text { Primary energy consumption } \\
\mathrm{kWh} / \mathrm{m} 2\end{array}$ \\
\hline Heating consumption & 1.5 & 1.95 & 2.9 \\
Domestic Hot Water consumption & 2.8 & 1.95 & 5.4 \\
Lighting consumption & 6.5 & 1.95 & 12.7 \\
Cooling consumption & 7.4 & 1.95 & 14.5 \\
Equipment consumption & 19.9 & 1.95 & 38.9 \\
\hline TOTAL & 38.1 & & 74.4 \\
\hline
\end{tabular}

The comfort inside the house was also examined to check the correct implementation of the designed algorithm. Three typical days with different climatic conditions were studied: a cold day in January, a warm day in July and a warm day in October (Fig. 6). It was observed that the indoor temperature (grey line in the upper graphs) was almost always in the range of indoor comfort. The variation of the outdoor temperature (blue line in the upper graphs) determined when it was necessary to ventilate the building naturally (grey line in the lower graphs). In a typical winter day (Fig. 6(a)), heating was activated during the night and natural ventilation cooled the dwelling in the early afternoon. In a typical summer day (Fig. 6(b)) cooling was activated during the day when outside temperature was close to $30^{\circ} \mathrm{C}$ and natural ventilation acclimatised the dwelling at night when outside temperature was stable. The typical autumn/spring day (Fig. 6(c)), shows how mechanical ventilation during evening, night and morning, in conjunction with natural ventilation activated in the early afternoon, are able to maintain indoor comfort without the need of activate any air conditioning system. Once the energy efficiency of the building was demonstrated in the current scenario, this research investigate how the impact of climate change would affect the dwelling's energy in the future. 


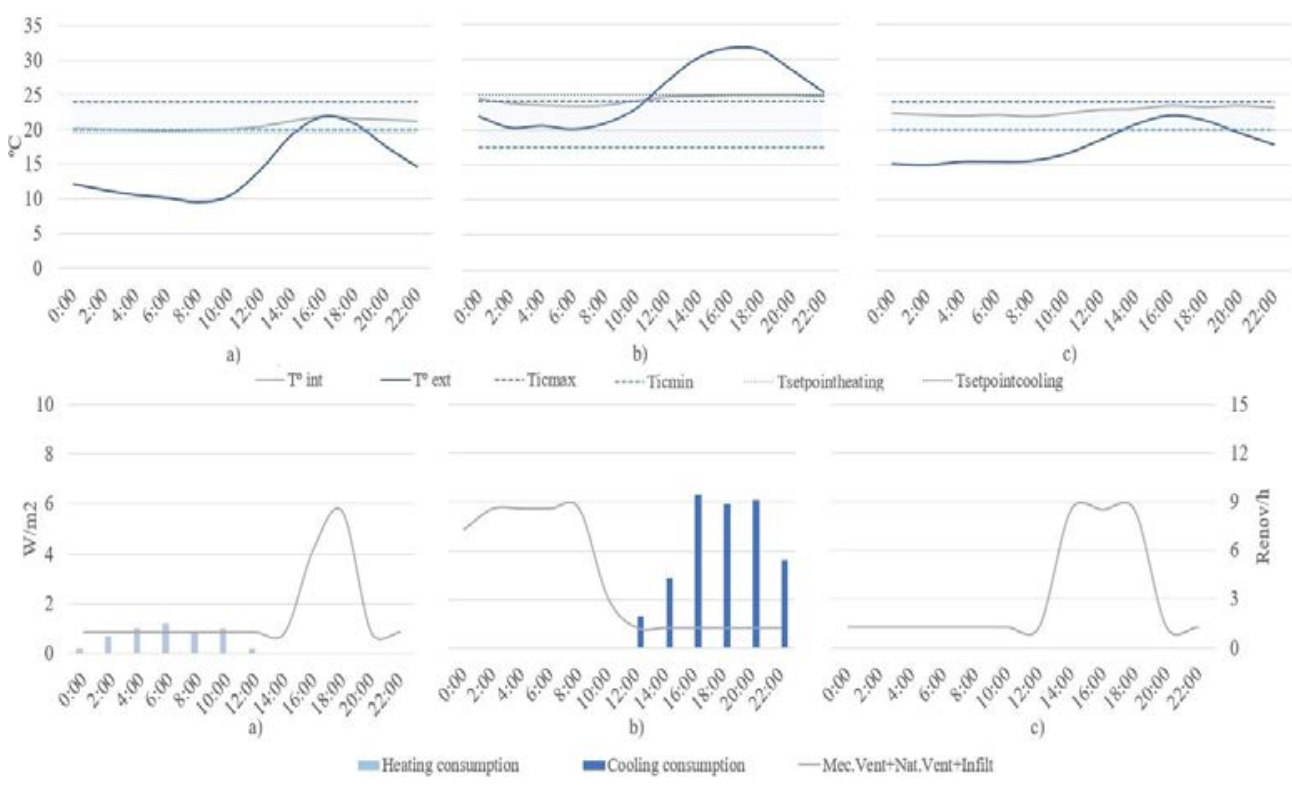

Figure 6: Temperature variation and operation of HVAC systems per hour. (a) Typical day in January; (b) Typical day in July; and (c) Typical day in October.

\section{RESULTS}

\subsection{Evaluation of the future climate in Malaga, Spain}

The average temperature and relative humidity variations per month were examined for the three time periods 2020, 2050 and 2080, and the four previously mentioned scenarios B1, B2, A2, A1F1 (Fig. 7). These climate variables were compared with the baseline taken as reference in the historical climate data file.

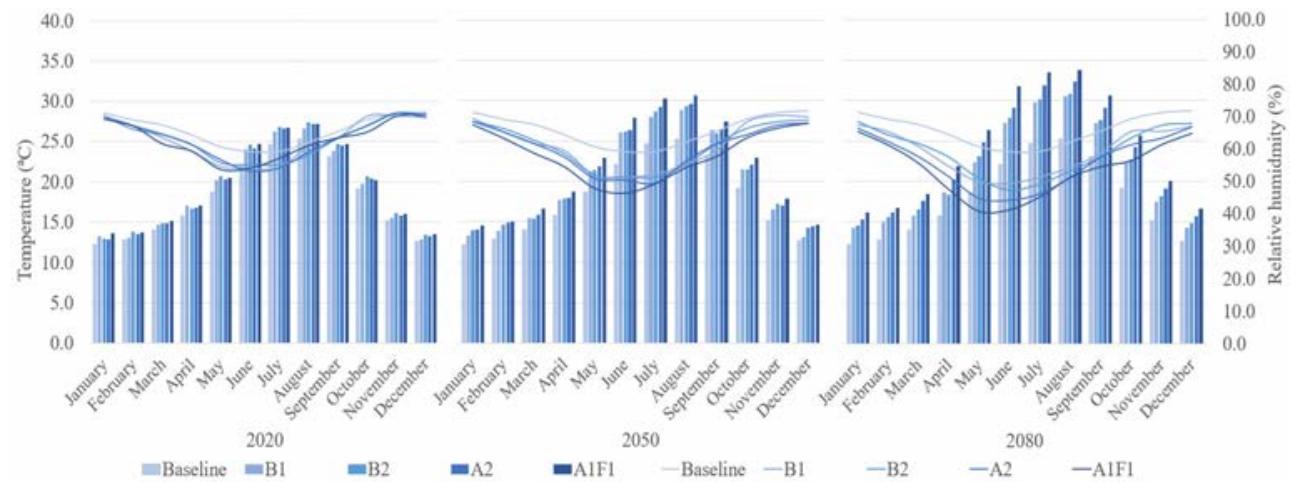

Figure 7: Variation of average temperature and relative humidity per month in 2020, 2050 and 2080 . 
In 2020 a slight increase of $0.8^{\circ} \mathrm{C}$ on average in the coldest months, $1.8^{\circ} \mathrm{C}$ in the hottest months and around $1{ }^{\circ} \mathrm{C}$ in the mildest months are predicted. In terms of relative humidity, a decrease in winter months (1.7\%) and summer months (3.1\%) are predicted too. In 2050 the average temperature in the cold months is expected to increase around $1.6^{\circ} \mathrm{C}$. With this variation the average temperatures of December $\left(13-14.6^{\circ} \mathrm{C}\right)$ and February $\left(13.8-15^{\circ} \mathrm{C}\right)$ in 2050 may be comparable to the current average temperatures of autumn and spring months. On the other hand, it is expected an increase in the average temperature of $4.1^{\circ} \mathrm{C}$ in summer months and $2.4^{\circ} \mathrm{C}$ in spring and autumn months. Therefore, the temperatures predicted for May $\left(21.3-22.9^{\circ} \mathrm{C}\right)$ and October $\left(21.5-22.9^{\circ} \mathrm{C}\right)$ in this period would be similar to current summer temperatures. With respect to relative humidity, it is estimated a decrease around $3.5 \%$ in winter and $7.6 \%$ in summer. In 2080 it is predicted an overall temperature increase about $2.8^{\circ} \mathrm{C}$ in winter months. Consequently, the average temperature of these months would be over $15^{\circ} \mathrm{C}$. In the case of summer months, the temperature increase predicted is about $6.4^{\circ} \mathrm{C}$ yielding a hotter summer over $30^{\circ} \mathrm{C}$. In terms of relative humidity, the months with the least decrease are December, January and February (5\%) while during the summer months (May, June and July) this effect is expected to be larger (15\%).

\subsection{Changes in energy consumption in different scenarios}

The variation in total energy consumption, $\mathrm{CO}_{2}$ emissions and heating and cooling demands in the dwelling were examined. They were also studied in the three periods and four scenarios mentioned and compared with the data from the current simulation, which is called baseline (Fig. 8, Table 2). The total energy consumption in the model building is expected to increase in each scenario, being lower in the scenarios where the impact of climate change is more mitigated (B1 and B2) and higher in the more adverse scenarios (A2 and A1F1). This trend is similar in the building's $\mathrm{CO}_{2}$ emissions.

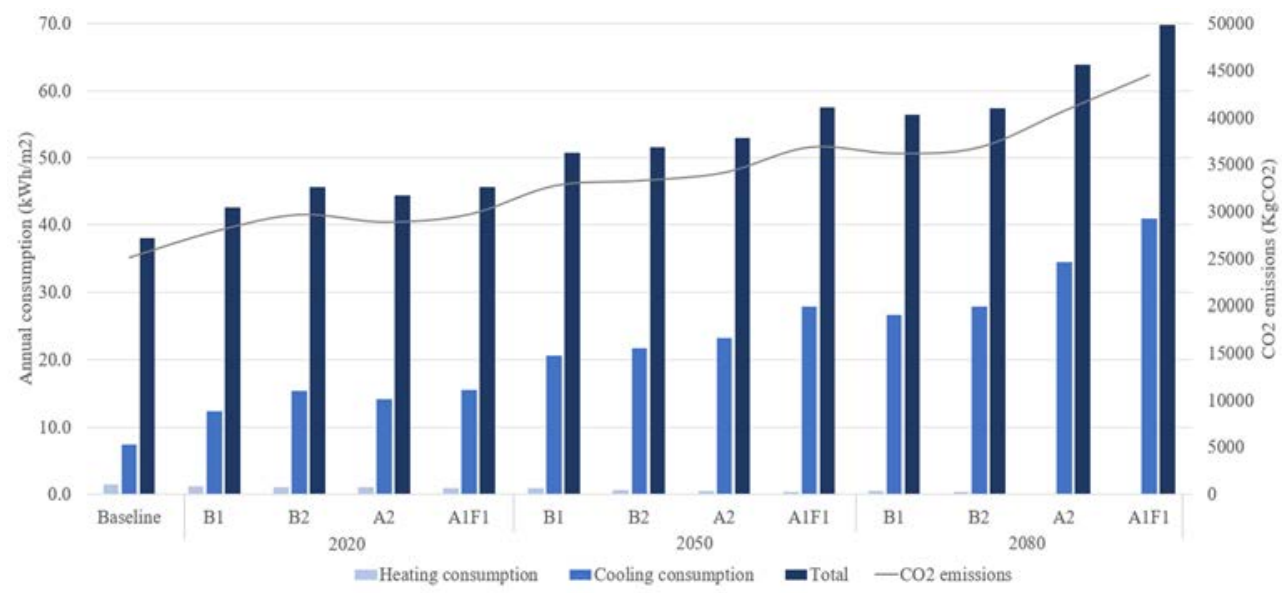

Figure 8: Variation of energy consumption and $\mathrm{CO}_{2}$ emissions in 4 IPCC scenarios in 2020, 2050 and 2080. 
Table 2: Summary of energy consumption and $\mathrm{CO}_{2}$ emissions in 4 IPCC scenarios in 2020, 2050 and 2080.

\begin{tabular}{|c|c|c|c|c|c|}
\hline Scenario & Energy Type & $\mathrm{kWh} / \mathrm{m} 2$ & Change & $\begin{array}{c}\mathrm{CO} 2 \text { emissions } \\
\mathrm{kgCO} 2 / \mathrm{m} 2\end{array}$ & Change \\
\hline \multirow{3}{*}{ BASELINE } & Heating & 1.5 & & & \\
\hline & Cooling & 7.4 & & & \\
\hline & Total & 38.1 & & 25136 & \\
\hline \multirow{3}{*}{ B1 2020} & Heating & 1.2 & $-20 \%$ & & \\
\hline & Cooling & 12.3 & $66 \%$ & & \\
\hline & Total & 42.6 & $12 \%$ & 27905 & $11 \%$ \\
\hline \multirow{3}{*}{ B2 2020} & Heating & 1.0 & $-33 \%$ & & \\
\hline & Cooling & 15.4 & $108 \%$ & & \\
\hline & Total & 45.7 & $20 \%$ & 29694 & $18 \%$ \\
\hline \multirow{3}{*}{ A2 2020} & Heating & 1.1 & $-27 \%$ & & \\
\hline & Cooling & 14.1 & $91 \%$ & & \\
\hline & Total & 44.4 & $17 \%$ & 28905 & $15 \%$ \\
\hline \multirow{3}{*}{ AlF1 2020} & Heating & 0.9 & $-40 \%$ & & \\
\hline & Cooling & 15.6 & $111 \%$ & & \\
\hline & Total & 45.7 & $20 \%$ & 29723 & $18 \%$ \\
\hline \multirow{3}{*}{ B1 2050} & Heating & 0.9 & $-40 \%$ & & \\
\hline & Cooling & 20.6 & $178 \%$ & & \\
\hline & Total & 50.7 & $33 \%$ & 32756 & $30 \%$ \\
\hline \multirow{3}{*}{ B2 2050} & Heating & 0.6 & $-60 \%$ & & \\
\hline & Cooling & 21.8 & $195 \%$ & & \\
\hline & Total & 51.6 & $35 \%$ & 33305 & $32 \%$ \\
\hline
\end{tabular}

\begin{tabular}{|c|c|c|c|c|c|}
\hline Scenario & Energy Type & $\mathrm{kWh} / \mathrm{m} 2$ & Change & $\begin{array}{c}\mathrm{CO} 2 \text { emissions } \\
\mathrm{kgCO} 2 / \mathrm{m}_{2}\end{array}$ & Change \\
\hline \multirow{3}{*}{ BASELINE } & Heating & 1.5 & & & \\
\hline & Cooling & 7.4 & & & \\
\hline & Total & 38.1 & & 25136 & \\
\hline \multirow{3}{*}{ A2 2050} & Heating & 0.5 & $-67 \%$ & & \\
\hline & Cooling & 23.3 & $215 \%$ & & \\
\hline & Total & 53.0 & $39 \%$ & 34166 & $36 \%$ \\
\hline \multirow{3}{*}{ AlF1 2050} & Heating & 0.4 & $-73 \%$ & & \\
\hline & Cooling & 27.9 & $277 \%$ & & \\
\hline & Total & 57.5 & $51 \%$ & 36862 & $47 \%$ \\
\hline \multirow{3}{*}{ B1 2080} & Heating & 0.5 & $-67 \%$ & & \\
\hline & Cooling & 26.7 & $261 \%$ & & \\
\hline & Total & 56.4 & $48 \%$ & 36200 & $44 \%$ \\
\hline \multirow{3}{*}{ B2 2080} & Heating & 0.3 & $-80 \%$ & & \\
\hline & Cooling & 27.9 & $277 \%$ & & \\
\hline & Total & 57.4 & $51 \%$ & 36847 & $47 \%$ \\
\hline \multirow{3}{*}{ A2 2080} & Heating & 0.1 & $-93 \%$ & & \\
\hline & Cooling & 34.5 & $366 \%$ & & \\
\hline & Total & 63.9 & $68 \%$ & 40731 & $62 \%$ \\
\hline \multirow[b]{2}{*}{ AlF 12080} & Heating & 0.1 & $-93 \%$ & & \\
\hline & $\begin{array}{c}\text { Cooling } \\
\text { Total }\end{array}$ & $\begin{array}{l}40.9 \\
69.8\end{array}$ & $\begin{array}{l}453 \% \\
83 \%\end{array}$ & 44548 & $77 \%$ \\
\hline
\end{tabular}

In 2020 an increase in total energy consumption (12-20\%) is predicted, raising 4.5 $\mathrm{kWh} / \mathrm{m}^{2}$ in $\mathrm{B} 1$ scenario and $7.6 \mathrm{kWh} / \mathrm{m}^{2}$ in $\mathrm{A} 1 \mathrm{~F} 1 \mathrm{scenario}$. On the other hand, $\mathrm{CO}_{2}$ emissions are expected to increase less than $20 \%$. In 2050 an increase in total energy consumption is observed for every scenario (33-51\%), assuming an average change of $16 \mathrm{kWh} / \mathrm{m}^{2}$. The trend is similar for $\mathrm{CO}_{2}$ emissions, with an increase of 30-47\%. In 2080 the difference become more drastic between the different scenarios. In scenarios B1 and B2, a smaller increase is estimated (less than $20 \mathrm{kWh} / \mathrm{m}^{2}$ ). In scenarios A2 and A1F1, the expected increase may double the current total consumption (48-83\%). $\mathrm{CO}_{2}$ emissions are expected to increase more than $10,000 \mathrm{~kg}$ in the first two scenarios, and more than $15,000 \mathrm{~kg}$ in the last two.

The studied building has a cooling demand that dominates energy consumption in the current climate (19\% of total consumption) and in future projections. Due to the characteristics of the subtropical climate the demand for heating is minimal, which represents only the $3.9 \%$ of total consumption. While the demand for heating is expected to decrease gradually, becoming unnecessary around 2080, cooling consumption may increase uncontrollably as outdoor temperatures change due to global warming. In 2020 a reduction in heating demand of $20-40 \%$ and an increase in cooling demand of $66-111 \%$ is estimated. In 2050 heating consumption is expected to be a $50 \%$ of the used as reference $(0.9-0.4$ $\mathrm{kWh} / \mathrm{m}^{2}$ ). On the other hand, cooling consumption would triplicate the reference data $\left(20.6-27.9 \mathrm{kWh} / \mathrm{m}^{2}\right)$. Finally, in 2080 the heating load may decrease about $80 \%$ while the cooling load may increase in a range of $261-453 \%$. In terms of the cooling consumption, it represents an increase between $26.7-40.9 \mathrm{kWh} / \mathrm{m}^{2}$.

\section{DISCUSSION}

This research shows that the southern area of Spain, specifically the city of Malaga, will increase significantly it average temperature, more in summer than in winter. Likewise the climate will become drier as global warming becomes more pronounced, mainly in the summer months. A significant rise is expected on the use of electricity for cooling, which will increase the total energy consumption in the building. The results of the future simulations show high percentages of variation in energy consumptions. This is mainly due 
to the design of HVAC systems, which was made assuming an invariable outdoor temperature based on the historical weather of Malaga. These systems were regulated according to the reference outdoor temperature, as shown in the algorithm of section 2 of this article.

In the current situation simulation the use of cooling was minimal due to it was replaced by natural ventilation. This strategy limits the entry of outside air when the temperature is above $24^{\circ} \mathrm{C}$. This value is suitable in the current climate situation, but it is inappropriate in the calculated climate change scenarios as it involve an excessive use of cooling system. According to this fact, it would be necessary to re-examine the climate design criteria and recalculate the internal comfort temperatures periodically. Some authors have proposed other alternatives to reduce electricity consumption in buildings. These are technological advances that make it possible to maintain indoor comfort without overusing air conditioning systems [27], [28].

Generally, each building requires a different study to calculate the impact of climate change on it. The use of the building also has a direct influence on the consumption of electricity, regardless of the type of climate. This has been demonstrated by other authors such as Jiang and O'Meara [29], who studied the impact of climate change on various buildings of different uses in a hot climate such as Florida. They concluded that public buildings, such as commercial buildings, will increase their demand for cooling to $110 \mathrm{kWh} / \mathrm{m}^{2}$, while residential buildings will increase their demand by approximately half. This was also demonstrated by Jiang et al. [16] and Wang and Chen [9] who concluded that public buildings tend to have high internal loads, such as equipment and lighting, which overheat the interior space. The small proportion of windows in relation to the walls reduces the impact of natural ventilation preventing the exchange of heat. On the other hand, Frank [30] reached a similar conclusion in a continental climate such as Switzerland, where the demand for heating may be more reduced in public buildings (58\%) than in residential (44\%).

There are some limitations in this research like the limitations of the methodology for generating meteorological files. The occurrence and frequency of weather events, such as heat waves, storms or seasonal precipitation, cannot be predicted by the GCM.

\section{CONCLUSIONS}

Global climate change has increased public awareness of energy use and its environmental consequences. It has generated a great interest in energy consumption of buildings. In this research, data and statistical analyses were carried out in order to estimate the effects that climate change may have on the construction sector in southern Spain before the end of this century. The future energy consumptions could be increased in a range of $48-83 \%$ from the current values, which would involve large economic costs and social impacts that are not yet predictable.

Building designers, construction companies, developers and environmental policy makers need to determinate new strategies and energy efficiency measures for the building sector able to buffer the impact of climate change in future scenarios to really reduce the energy consumption in buildings.

\section{REFERENCES}

[1] Eurostat, Energy, Transport and Environment Indicators. 2014.

[2] Metz, B., Meyer, L. \& Bosch, P., Climate Change 2007: Mitigation of Climate Change, vol. $9780521880,2007$.

[3] NOAA, The first Climate Model in National Oceanic and Atmospheric Administration, Atmos. Agency, pp. 383-438, 2004. 
[4] Willby, R.L. \& Wigley, T.M.L., Downscaling general circulation model output: a review of methods and limitations. Progress in Physical Geography: Earth and Environment, 21(4), pp. 530-548, 1997.

[5] Belcher, E.E., Hacker, J.N. \& Powell, D.S., Constructing design weather data for future climates. Build. Serv. Eng. Res. Technol., 26(1), pp. 49-61, 2005.

[6] Wang, X., Chen, D. \& Ren, Z., Assessment of climate change impact on residential building heating and cooling energy requirement in Australia. Build. Environ., 45(7), pp. 1663-1682, 2010.

[7] Chan, A.L.S., Developing future hourly weather files for studying the impact of climate change on building energy performance in Hong Kong. Energy Build., 43(10), pp. 2860-2868, 2011.

[8] Zhu, M., Pan, Y., Huang, Z. \& Xu, P., An alternative method to predict future weather data for building energy demand simulation under global climate change. Energy Build., 113, pp. 74-86, 2016.

[9] Wang, H. \& Chen, Q., Impact of climate change heating and cooling energy use in buildings in the United States. Energy Build., 82, pp. 428-436, 2014.

[10] Shen, P., Impacts of climate change on U.S. building energy use by using downscaled hourly future weather data. Energy Build., 134, pp. 61-70, 2017.

[11] Wang, L., Liu, X. \& Brown, H., Prediction of the impacts of climate change on energy consumption for a medium-size office building with two climate models. Energy Build., 157, pp. 218-226, 2017.

[12] Jentsch, M.F., Bahaj, A.B.S. \& James, P.A.B., Climate change future proofing of buildings-Generation and assessment of building simulation weather files. Energy Build., 40(12), pp. 2148-2168, 2008.

[13] Jentsch, M.F., James, P.A.B., Bourikas, L. \& Bahaj, A.B.S., Transforming existing weather data for worldwide locations to enable energy and building performance simulation under future climates. Renew. Energy, 55, pp. 514-524, 2013.

[14] Sabunas, A. \& Kanapickas, A., Estimation of climate change impact on energy consumption in a residential building in Kaunas, Lithuania, using HEED Software. Energy Procedia, 128, pp. 92-99, 2017.

[15] Jiang, A., Zhu, Y., Elsafty, A. \& Tumeo, M., Effects of global climate change on building energy consumption and its implications in Florida. Int. J. Constr. Educ. Res., 14(1), pp. 22-45, 2018.

[16] Jiang, A., Liu, X., Czarnecki, E. \& Zhang, C., Hourly weather data projection due to climate change for impact assessment on building and infrastructure. Sustain. Cities Soc., 50, 2019.

[17] Lam, T.N.T., Wan, K.K.W., Wong, S.L. \& Lam, J.C., Impact of climate change on commercial sector air conditioning energy consumption in subtropical Hong Kong. Appl. Energy, 87(7), pp. 2321-2327, 2010.

[18] Wan, K.K.W., Li, D.H.W. \& Lam, J.C., Assessment of climate change impact on building energy use and mitigation measures in subtropical climates. Energy, 36(3), pp. 1404-1414, 2011.

[19] De Vecchi, R., Candido, C., de Dear, R. \& Lamberts, R., Thermal comfort in office buildings: Findings from a field study in mixed-mode and fully-air conditioning environments under humid subtropical conditions. Build. Environ., 123, pp. 672-683, 2017.

[20] United States Department of Energy, Weather Data|EnergyPlus. https://energyplus.net/weather. Accessed: 6 Apr. 2020. 
[21] University of North Florida, Weather Morph: Climate Change Weather File Generator|UNF. http://139.62.210.131/weatherGen/. Accessed: 6 Apr. 2020.

[22] IPCC, IPCC Special Report on Emissions Scenarios (SRES): Summary for policymakers - A special report of IPCC working group III intergovernmental panel on climate change, Geneva, Switz.

[23] Melgar, S.G., Bohórquez, M.Á.M. \& Márquez, J.M.A., UhuMEB: Design, construction, and management methodology of minimum energy buildings in subtropical climates. Energies, 11(10), pp. 1-34, 2018.

[24] Gómez Melgar, S., Martínez Bohórquez, M.Á. \& Andújar Márquez, J.M., uhuMEBr: Energy Refurbishment of Existing Buildings in Subtropical Climates to Become Minimum Energy Buildings. Energies, 13(5), p. 1204, 2020.

[25] Cordero, A.S., Melgar, S.G. \& Márquez, J.M.A., Green building rating systems and the new framework level(s): A critical review of sustainability certification within Europe. Energies, 13(1), pp. 1-25, 2019.

[26] Nicol, J.F. \& Humphreys, M.A., Adaptive thermal comfort and sustainable thermal standards for buildings. Energy and Buildings, 34(6), pp. 563-572, 2002.

[27] Márquez, J.M.A., Bohórquez, M.Á.M. \& Melgar, S.G., Ground thermal diffusivity calculation by direct soil temperature measurement. application to very low enthalpy geothermal energy systems. Sensors (Switzerland), 16(3), p. 306, 2016.

[28] Andújar Márquez, J.M., Martínez Bohórquez, M.Á. \& Gómez Melgar, S., A new metre for cheap, quick, reliable and simple thermal transmittance (U-value) measurements in buildings. Sensors (Basel), 17(9), 2017.

[29] Jiang, A. \& O'Meara, A., Accommodating thermal features of commercial building systems to mitigate energy consumption in Florida due to global climate change. Energy Build., 179, pp. 86-98, 2018.

[30] Frank, T., Climate change impacts on building heating and cooling energy demand in Switzerland. Energy Build., 37(11), pp. 1175-1185, 2005. 